\title{
Sex Differences and Hormonal Influences on Acquisition of Cocaine Self-Administration in Rats
}

\author{
Lisa R Jackson', Terry E Robinson ${ }^{2,3}$ and Jill B Becker*,2,3,4 \\ 'Department of Psychiatry, The University of Michigan, Ann Arbor, MI, USA; ²Department of Psychology, The University of Michigan, Ann Arbor, \\ MI, USA; ${ }^{3}$ Neuroscience Program, The University of Michigan, Ann Arbor, MI, USA; ${ }^{4}$ Reproductive Sciences Program, The University of Michigan, \\ Ann Arbor, MI, USA
}

\begin{abstract}
Men and women differ in their response to cocaine, and a woman's response varies with the menstrual cycle. For example, women have greater subjective responses to cocaine in the follicular phase of the menstrual cycle when estradiol is predominant, than they do during the luteal phase when both estradiol and progesterone are elevated. Similarly, female rats show significantly more cocaine-induced locomotor behavior and cocaine self-administration during behavioral estrus, shortly after estradiol peaks, than during other stages of the cycle, and estradiol administration to ovariectomized (OVX) females enhances the acquisition of cocaine self-administration. The purpose of this study was to expand upon these findings by studying the effects of progesterone administration to females, and estradiol administration to males, on acquisition of cocaine self-administration. We report here that there are both sex differences in and effects of circulating ovarian hormones on acquisition of cocaine self-administration. We demonstrate that although estradiol administration enhances acquisition of cocaine self-administration in OVX female rats, concurrent administration of progesterone with estradiol inhibits this effect of estradiol. In a separate experiment, we demonstrate that estradiol administration does not enhance acquisition of cocaine self-administration in castrated male rats. We conclude that $(I)$ there is a sex difference in the effects of estradiol on cocaine selfadministration: it facilitates acquisition in female, but not male rats; and that (2) in females concurrent progesterone treatment counteracts the facilitory effect of estradiol on cocaine self-administration.
\end{abstract}

Neuropsychopharmacology (2006) 3 I, 129-138. doi: I 0. I038/s..npp. I 300778; published online 25 May 2005

Keywords: cocaine; estrogen; progesterone; drug abuse; sex differences; self-administration

\section{INTRODUCTION}

Cocaine use by women has increased in the last decade, and women now account for approximately $40 \%$ of regular cocaine users (Greenblatt and Gfroerer, 1998). The increase in cocaine use by young women poses a serious public health concern because women may be more vulnerable to psychomotor stimulant drugs than men. Women have a disproportionately greater lifetime dependence upon cocaine, relative to alcohol and marijuana, which are used more often by both men and women (Kandel et al, 1995). Men report lifetime dependence proportionate with their use of other substances (Kandel et al, 1995). Moreover, women begin using cocaine and enter treatment programs at earlier ages than men (Lynch et al, 2002). By the time they

*Correspondence: Dr JB Becker, Department of Psychology, University of Michigan, 525 East University, Ann Arbor, MI 48I09-1 I09, USA, Tel: + I 734763 4363, Fax: + I 734763 7480,

E-mail: jbbecker@umich.edu

Received 30 November 2004; revised 19 April 2005; accepted 20 April 2005

Online publication: 21 April 2005 at http://www.acnp.org/citations/ NPP042 10504055 |/default.pdf enter treatment, women have used cocaine for a significantly shorter period of time, have more severe drug problems, and have poorer psychological functioning than do men (Griffin et al, 1989; Lex, 1991; Kosten et al, 1993).

Although intrinsic sex differences in brain organization may be partially responsible for sex differences in responses to psychomotor stimulants, circulating gonadal hormones are also thought to play a role in modulating vulnerability to drug use in women. For example, females report a greater subjective response to both cocaine (Evans et al, 2002; Sofuoglu et al, 1999) and amphetamine (AMPH) (Justice and de Wit, 1999; White et al, 2002) in the follicular phase of the menstrual cycle, when estradiol is predominant, as compared to the luteal phase, when both estradiol and progesterone are elevated. Furthermore, AMPH-induced subjective effects are positively correlated with salivary estradiol levels and negatively correlated with progesterone levels (White et al, 2002). These results suggest that, in women, estradiol may potentiate the subjective responses to psychomotor stimulants compared to the effects of estradiol and progesterone together.

Female rats have been shown to acquire cocaine selfadministration more quickly than males (Lynch and Carroll, 
1999; Carroll et al, 2002), and cocaine self-administration in female rodents varies across the estrous cycle (Lynch et al, 2000). When tested under a progressive ratio schedule of responding for cocaine, female rats reach a greater ratio of lever presses to infusions of cocaine (ie a higher breaking point) on behavioral estrus, than they do during other phases of the cycle; females also have higher breaking points than male rats (Roberts et al, 1989). In contrast, sucrose self-administration does not vary across the estrous cycle (Hecht et al, 1999). Although estrous/menstrual cycle effects demonstrate the involvement of ovarian hormones, they do not identify which specific ovarian hormones are involved.

Estradiol administration to ovariectomized (OVX) females affects many psychomotor stimulant drug-induced behaviors, including self-administration (Verimer et al, 1981; Peris et al, 1991; Thompson and Moss, 1994; Sircar and Kim, 1999; Grimm and See, 1997; Becker, 1999; Quinones-Jenab et al, 2000; Lynch et al, 2001). For example, $\mathrm{Hu}$ et al (2004) found that in OVX female rats, exogenous estradiol treatment alone was sufficient to facilitate acquisition of cocaine self-administration. Estradiol-facilitated cocaine self-administration has also been shown in other studies (Roberts et al, 1989; Lynch et al, 2001). It is unknown, however, whether estradiol has a similar effect on males. Therefore, one purpose of the present study was to determine the effect of estradiol treatment on the acquisition of cocaine self-administration in males.

In contrast to estradiol, salivary progesterone levels were negatively correlated with the positive subjective effects of psychomotor stimulant drugs (White et al, 2002). Furthermore, in OVX female rats treated with estradiol, progesterone administration inhibited cocainemediated behaviors such as estradiol-enhanced locomotor activity and sensitization of cocaine-induced stereotyped behavior (Peris et al, 1991; Quinones-Jenab et al, 2000). Thus, a second goal of the present study was to determine the effect of progesterone on the ability of estradiol to facilitate the acquisition of cocaine self-administration behavior.

\section{MATERIALS AND METHODS}

\section{Animals}

Adult female and male Sprague-Dawley rats (64-76 days old) were purchased from Harlan Inc. (Indianapolis, IN). They were housed in groups of 2-4 per cage until catheter implantation, after which animals were individually housed. The animal colony temperature was maintained at a constant temperature of $20-21^{\circ} \mathrm{C}$. Animals were fed an alfalfa- and soy-free, low phytoestrogen food (2014 Teklad Global Harlan rat chow; Harlan Teklad, Madison, WI) ad libitum and water was available ad libitum. Lighting was maintained on a 14:10 reverse light/dark schedule with lights off at 0500 . Testing was conducted at 0800 . At the start of testing, females weighed $250-260 \mathrm{~g}$, and males weighed $270-280 \mathrm{~g}$. All procedures were performed according to a protocol approved by the University of Michigan Committee on Use and Care of Animals. Different animals were used in Experiments 1 and 2.

\section{Surgical Procedures}

Approximately 1 week after arrival, all females were bilaterally OVX, and males underwent castration or sham surgery under isoflurane anesthesia $(5 \%$ isoflurane in oxygen). In order to verify lack of estrous cycling, vaginal epithelia cells were examined via microscope daily for at least 10 consecutive days beginning 5 days after OVX. No animals exhibited cornified epithelial cells from the vaginal smears; thus, all OVX females were included in the experiment. Males were also handled daily during this time.

Approximately 2-3 weeks after gonadectomy or sham surgery, rats received implants of indwelling intravenous (i.v.) jugular catheters connected to a back port. Jugular catheter implantation was based on previously described procedures ( $\mathrm{Hu}$ et al, 2004). Briefly, catheters were constructed by using medical adhesive (Dow Corning, Midland, MI) to connect silastic tubing $(0.51 \mathrm{~mm} \mathrm{ID \text {, }}$ $0.94 \mathrm{~mm} \mathrm{OD)} \mathrm{to} \mathrm{an} \mathrm{external} \mathrm{back} \mathrm{port} \mathrm{connector} \mathrm{mount}$ (Plastics One, Roanoke, VA). Rats were anesthetized with ketamine $(50 \mathrm{mg} / \mathrm{kg})$ and Domitor $(0.5 \mathrm{mg} / \mathrm{kg}$ for males, and $0.4 \mathrm{mg} / \mathrm{kg}$ for females; Pfizer Inc., New York, NY). The free end of the silastic tubing was inserted into the right jugular vein and secured with 4.0 silk sutures around the venous tissue. Catheters exited dorsally between the scapulae. Animals received Antisedan $(0.5 \mathrm{mg} / \mathrm{kg}$ for males, and $0.4 \mathrm{mg} / \mathrm{kg}$ for females; Pfizer Inc.) after surgery to reverse the effects of Domitor. Dummy cannulae were inserted into the catheters when animals were not connected to the infusion system. Animals were housed individually following catheterization surgery. Catheters were flushed daily with $0.1 \mathrm{ml}$ gentamicin $(0.008 \mathrm{mg} / \mathrm{ml})$ to prevent microbial buildup in the catheter. Animals also received $0.1 \mathrm{ml}$ heparinized saline $(35 \mathrm{U} / \mathrm{ml}$ in $0.9 \%$ sterile injectible saline) three times per week via the catheter to prevent occlusions. Prior to the beginning of each session, catheters were flushed with $0.1 \mathrm{ml}$ sterile saline.

\section{General Self-Administration Procedures}

At 1 week after recovery from catheter implantation surgery, rats were placed into standard operant chambers $(41 \times 24 \mathrm{~cm}$ floor, $26 \mathrm{~cm}$ high; Med Associates, St Albans, $\mathrm{VT})$, connected to an infusion syringe, and tethered via a steel cable to a swivel, which was mounted on a counterbalanced arm. This allowed animals to move freely in the chamber. At the start of each $1 \mathrm{~h}$ session, the house light illuminated the chamber. Rats were then allowed to nose poke to obtain an i.v. infusion of cocaine on an FR1 schedule of reinforcement. Each nose poke in the active port produced a compound stimulus consisting of illumination of the nose hole port, a tone ( $85 \mathrm{~dB})$, and an i.v. injection of $50 \mu \mathrm{l}$ of cocaine $\mathrm{HCl}$ (National Institute on Drug Abuse, Research Triangle Park, NC) in $0.9 \%$ saline delivered over $2.8 \mathrm{~s}$. The concentration of cocaine was adjusted for each rat such that all rats, male and female, received the same $\mathrm{mg} / \mathrm{kg}$ dose of cocaine. The infusion was followed by a $5 \mathrm{~s}$ time-out period during which further nose pokes were recorded, but had no effect. Nose pokes in the inactive hole were also recorded, but they had no consequence. At the end of each session, catheters were flushed with $0.1 \mathrm{ml}$ gentamicin $(0.008 \mathrm{mg} / \mathrm{ml})$. 


\section{Experimental Design}

Experiment 1: effect of concurrent progesterone and estradiol administration on acquisition of cocaine selfadministration in OVX rats. Five groups of rats were tested as follows: (1) OVX $+\mathrm{E}(n=15)-\mathrm{OVX}$ females were treated with $5 \mu \mathrm{g}$ estradiol benzoate (EB) in $0.1 \mathrm{ml}$ peanut oil $30 \mathrm{~min}$ prior to each self-administration session; (2) $\mathrm{OVX}+\mathrm{E}+\mathrm{P}(n=15)-\mathrm{OVX}$ females were treated with $5 \mu \mathrm{g}$ $\mathrm{EB}$ and $125 \mu \mathrm{g}$ progesterone in $0.2 \mathrm{ml}$ peanut oil $30 \mathrm{~min}$ prior to each self-administration session; (3) OVX $(n=15)$-OVX females were treated with $0.1 \mathrm{ml}$ peanut oil vehicle (s.c.); as were groups (4) CAST $(n=15)-$ castrated males; and (5) SHAM $(n=15)$ - sham-castrated (gonadally intact) males.

Experiment 2: effect of estradiol administration in CAST male rats on acquisition of cocaine self-administration. Five groups of rats were tested as follows: (1) OVX females and (2) castrated males that received $5 \mu \mathrm{g} \mathrm{EB}$ in $0.1 \mathrm{ml}$ peanut oil (s.c.) $30 \mathrm{~min}$ prior to each self-administration test session (OVX $+\mathrm{E}, n=15 ; \mathrm{CAST}+\mathrm{E}, n=15)$; (3) OVX females; (4) castrated males; and (5) shamcastrated males that received vehicle $30 \mathrm{~min}$ prior to each self-administration test session (OVX, $n=30$; CAST, $n=15$; SHAM; $n=15)$. Of the OVX females, 15 were pretreated with $5 \mu \mathrm{g}$ EB for 12 days, ending 10 days before the start of testing, but they were not significantly different from other OVX females; thus, data for these females were collapsed.

We did not test a progesterone-only group because in previous experiments the administration of progesterone alone did not influence psychomotor stimulant-induced behavior (Becker and Rudick, 1999; Disshon et al, 1998; Peris et al, 1991; Perrotti et al, 2001; Quinones-Jenab et al, 2000). For example, in OVX rats, hormone replacement with estradiol alone, but not progesterone alone, resulted in greater cocaine-evoked hyperactivity than was observed in nontreated OVX animals (Sell et al, 2000). Furthermore, in a study with several strains of rats, progesterone alone did not alter the OVX-induced attenuation of cocaine-induced locomotor behavior; however, estradiol alone restored cocaine-induced behavioral sensitization (Sircar and Kim, 1999).

The testing protocol and doses were the same as published previously ( $\mathrm{Hu}$ et al, 2004). Briefly, rats were tested Monday-Friday for 3 consecutive weeks, with the dose of cocaine increasing each week, beginning Week 1 with $0.3 \mathrm{mg} / \mathrm{kg}$ per infusion, $0.4 \mathrm{mg} / \mathrm{kg}$ per infusion during Week 2 , and ending at $0.5 \mathrm{mg} / \mathrm{kg}$ per infusion during Week 3. This regimen allowed us to examine the effect of dose on the acquisition of cocaine self-administration behavior. Serum estradiol concentrations with this dosing regimen are in the physiological range comparable to proestrus ( $\mathrm{Hu}$ et al, 2004). The selected progesterone dose was one which was low, yet has measurable behavioral effects, inducing lordosis in OVX females primed with EB (White and Uphouse, 2004).

At the beginning and end of each week, catheters were tested for patency by injecting $0.1 \mathrm{ml}$ short-acting Pentothal (thiopental sodium $20 \mathrm{mg} / \mathrm{ml}$ in sterile water; Abbott Laboratories, Abbott Park, IL) into the catheter. Rats that did not become ataxic within $3 \mathrm{~s}$ were excluded from analysis.

Laboratories use a variety of criteria for defining acquisition of drug self-administration. Based on previous work from this laboratory, acquisition was defined as responding on the active hole at a rate $25 \%$ greater than the basal responding rate (8) for three consecutive sessions. Thus, if a rat attained 10 infusions per dose for three consecutive test sessions, it was considered to have acquired self-administration behavior.

\section{Data Analysis}

Comparisons among groups were made by analysis of variance (ANOVA) to compare effects of hormones across the five test sessions at each dose. Subsequent Bonferroni post hoc comparisons were performed to compensate for multiple comparisons. Acquisition data were analyzed by $\chi^{2}$. For planned comparisons between OVX and CAST groups in Experiment 2, individual ANOVA was conducted for each day of self-administration. Groups were considered to be significantly different if $p<0.05$. Statistical analyses were performed using StatView 4.5 (Systat, Evanston, IL) for Macintosh (Apple Computers, Cupertino, CA) and SPSS 13.0 (SPSS, Chicago, IL) for Windows (Microsoft Corporation, Redmond, WA).

\section{RESULTS}

\section{Experiment 1: Effect of Concurrent Progesterone and Estradiol Administration on Acquisition of Cocaine Self-Administration in OVX Rats}

Coadministration of progesterone with estradiol prevented the estradiol-induced enhancement of the acquisition of cocaine self-administration. Figure 1 shows the average number of cocaine infusions taken by each group during the 3 weeks of testing. During Week $1(0.3 \mathrm{mg} / \mathrm{kg} /$ infusion; Figure 1a), there was a main effect of hormone treatment group $\left(\mathrm{F}_{(4,4)}=32.6, \quad p<0.0001\right)$, no effect of test day $\left(\mathrm{F}_{(4,16)}=2.1, p<0.0795\right)$, and a group $\times$ day interaction $\left(\mathrm{F}_{(16,416)}=1.8, p<0.0272\right)$. Post hoc comparisons indicated that on the first 2 days of testing, there were no differences among the groups. Beginning on day 3 , however, the OVX + E group took significantly more cocaine infusions than all other groups (day 3: $p<0.0014$; day 4: $p<0.0001$; day 5: $p<0.0001$ ), which did not differ from one another. There were no group differences in the number of nose pokes in the inactive hole. During Week 2 (0.4 mg/kg/infusion; Figure $1 \mathrm{~b})$, there was a main effect of hormone treatment group $\left(\mathrm{F}_{(4,4)}=29.438, p<0.0001\right)$, no effect of test day $\left(\mathrm{F}_{(4,16)}=1.485, p<0.21\right)$, and no group $\times$ day interaction $\left(\mathrm{F}_{(16,328)}=0.352, p<0.99\right)$. Again, on each test day, the OVX + E group took significantly more cocaine than all other groups, which did not differ from one another, and there were no group differences in inactive hole nose pokes. During Week $3(0.5 \mathrm{mg} / \mathrm{kg} /$ infusion; Figure $1 \mathrm{c})$, there was a main effect of hormone treatment group $\left(\mathrm{F}_{(4,4)}=14.7\right.$, $p<0.0001)$, an effect of test day $\left(\mathrm{F}_{(4,16)}=4.95, p<0.0008\right)$, and no group $\times$ day interaction $\left(\mathrm{F}_{(16,200)}=0.39, p<0.98\right)$. On test days $11-14$, the OVX $+\mathrm{E}$ group took significantly more cocaine than all other groups, which did not differ 
from one another, until day 15 , when there were no differences among any of the groups. There were no group differences in inactive hole nose pokes.

Figure 2 provides a summary of the mean $( \pm$ SEM) cocaine intake (total $\mathrm{mg} /$ week) as a function of group, during each of the 3 weeks of testing. There was an effect of hormone treatment group $\mathrm{F}_{(4,4)}=32.6, p<0.0001$, no effect of dose $\mathrm{F}_{(4,16)}=2.1, p<0.0795$, and an interaction effect of hormone $\times$ dose $\mathrm{F}_{(16,416)}=1.8, p<0.0272$. The OVX $+\mathrm{E}$ group took more cocaine than all other groups, on all 3 weeks of testing, and the other groups did not differ from one another (Bonferroni post hoc tests). OVX $+\mathrm{E}$ attained
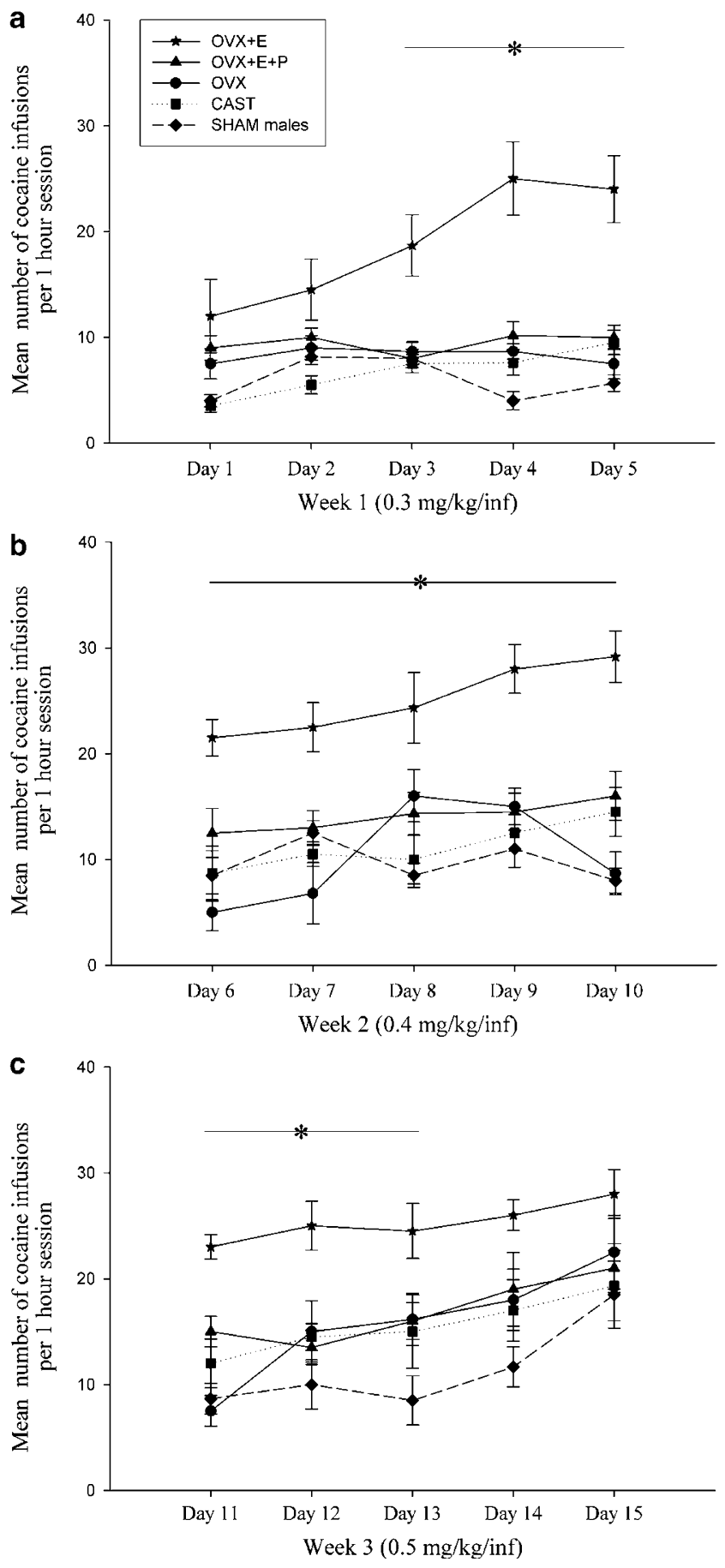

more cocaine infusions than all other groups. Week 1: $p<0.04$; Week 2: $(p<0.002)$; Week 3: $p<0.02-0.001$.

Figure 3 shows the percentage of rats that acquired selfadministration as a function of group and week of testing (dose). During Week 1,76.5\% of the OVX $+\mathrm{E}$ rats acquired self-administration behavior, whereas only $28.6 \%$ of OVX +

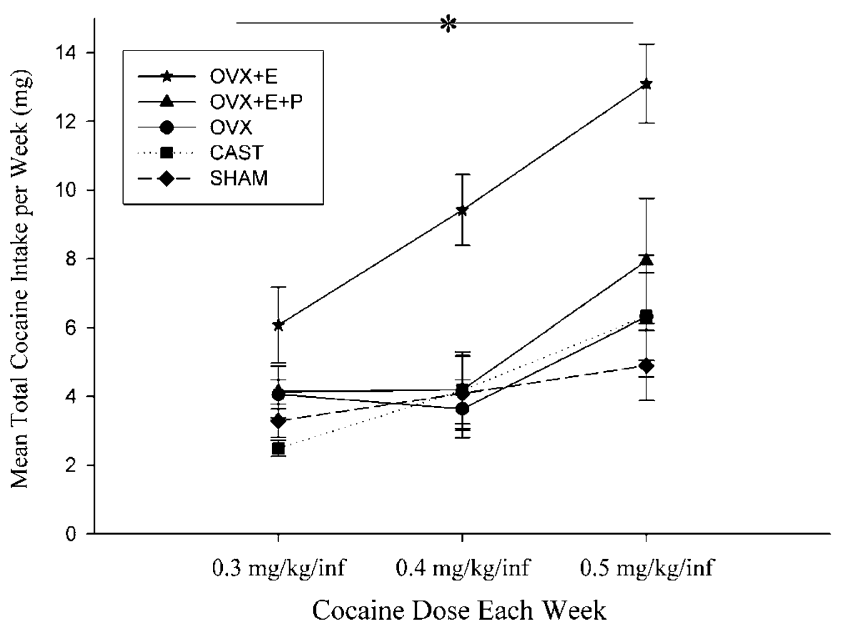

Figure 2 Mean total cocaine intake per week. Progesterone administration negatively affected the amount of cocaine ingested by ovariectomized females. The OVX $+E$ group obtained more cocaine than all other groups at each dose, the $\mathrm{OVX}+\mathrm{E}+\mathrm{P}$ group was not statistically significantly different from the oil-treated female group or other groups, and there was no difference between the CAST and SHAM male groups $(p<0.49)$ at any dose. Data points $=$ mean \pm SEM.

Figure I (a) Cocaine self-administration over the first five test sessions, This figure shows the mean number of cocaine infusions $( \pm S E M)$ taken by rats in the female: OVX $+E, O V X+E+P, O V X$; and male: CAST and SHAM groups during the first week of testing at $0.3 \mathrm{mg} / \mathrm{kg} /$ infusion. There was an effect of hormonal status $\left(F_{(4.4)}=32.6, p<0.0001\right)$, no effect of test day $\left(F_{(4,16)}=2.1, p<0.0795\right)$, and an interaction effect of hormone $\times$ test day $\left(F_{(16,416)}=1.8, p<0.0272\right)$. On the first 2 days of testing, there were no differences among the groups. Beginning on day 3 , however, the OVX $+\mathrm{E}$ group attained significantly more cocaine infusions than the other groups (day 3: $p<0.0014$; day 4: $p<0.000$ I; and day 5: $p<0.000$ I). Thus, from days 3 to 5 , the $\mathrm{OVX}+\mathrm{E}$ group had more infusions than all other groups and the $\mathrm{OVX}+\mathrm{E}+\mathrm{P}$ group had significantly fewer infusions. There were no group differences in activity at the inactive hole. Only the OVX+ E group met the criterion for acquisition at this dose. (b) Cocaine selfadministration during week 2 at $0.4 \mathrm{mg} / \mathrm{kg} /$ infusion. This figure shows the mean number of cocaine infusions $( \pm$ SEM) taken by rats in the female: $\mathrm{OVX}+\mathrm{E}, \mathrm{OVX}+\mathrm{E}+\mathrm{P}, \mathrm{OVX}$; and male: CAST and SHAM groups during the second week of testing at $0.4 \mathrm{mg} / \mathrm{kg} /$ infusion. There was an effect of hormonal status $\left(F_{(4,4)}=29.438, p<0.000 \mathrm{I}\right)$, no effect of test day $\left(F_{(4,16)}=1.485, p<0.21\right)$, and no interaction effect of hormone $x$ test day $\left(F_{(16,328)}=0.352, p<0.99\right)$. There were no group differences in activity at the inactive hole. The OVX $+E, O V X+E+P$, and CAST groups met the criterion for acquisition at this dose. (c) Cocaine self-administration during week $3-0.5 \mathrm{mg} / \mathrm{kg} /$ infusion. This figure shows the number of cocaine infusions $( \pm S E M)$ taken by rats in the female: OVX $+E, O V X+E+P$, OVX; and male: CAST and SHAM groups during the third week of testing at $0.5 \mathrm{mg} / \mathrm{kg} /$ infusion. There was an effect of hormonal status $\left(F_{(4,4)}=14.7\right.$, $p<0.000 \mathrm{I})$, an effect of test day $\left(F_{(4,16)}=4.95, p<0.0008\right)$, and no interaction effect of hormone $x$ test day $\left(F_{(16,200)}=0.39, p<0.98\right)$. There were no group differences in activity at the inactive hole. All groups met the criterion for self-administration at this dose except SHAM males. 


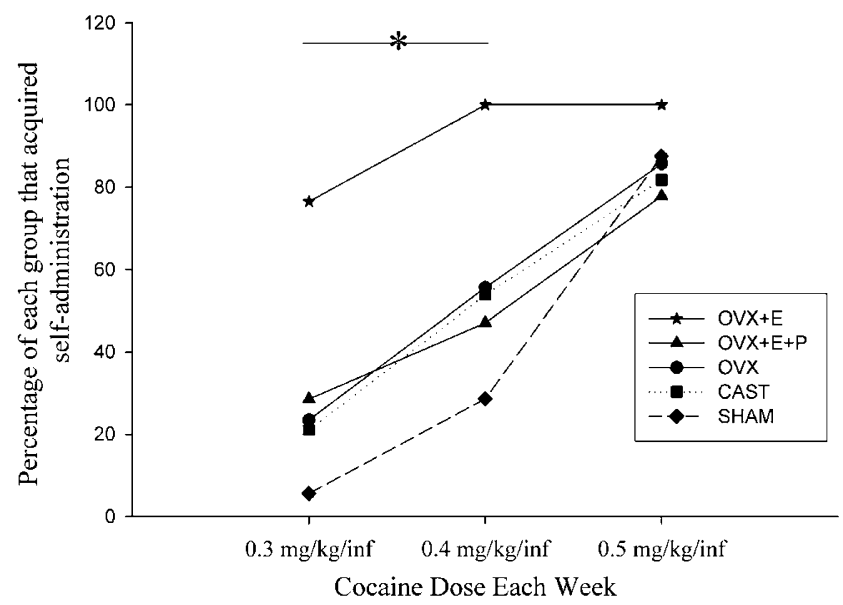

Figure 3 Percentage of animals in each group in Experiment I that met the criterion for acquisition of self-administration at each dose. The lowest dose of cocaine $(0.3 \mathrm{mg} / \mathrm{kg} / \mathrm{inf})$ was administered during Week I, and $76.5 \%$ of $\mathrm{OVX}+\mathrm{E}$ acquired self-administration behavior. There were no differences between other groups, as only $28.6 \%$ of OVX $+E+P, 23.5 \%$ of OVX, $21 \%$ of CAST, and $5.6 \%$ of SHAM males acquired at this dose. By Week 2, $100 \%$ of OVX $+E$ acquired self-administration behavior at $0.4 \mathrm{mg} /$ $\mathrm{kg} /$ infusion. There were no differences between other groups, as $47.1 \%$ of OVX $+E+P, 55.6 \%$ of OVX, $53.8 \%$ of CAST, and $28.6 \%$ of SHAM males acquired. By Week 3, almost all rats in each group acquired selfadministration behavior at $0.5 \mathrm{mg} / \mathrm{kg} /$ infusion. There were no differences between groups' acquisition of self-administration. Specifically $100 \%$ of OVX $+E, 77.8 \%$ of OVX $+E+P, 85.7 \%$ of OVX, $81.8 \%$ of CAST, and $87.5 \%$ of SHAM males acquired self-administration.

$\mathrm{E}+\mathrm{P}, 23.5 \%$ of OVX females, $21 \%$ of CAST, and $5.6 \%$ of SHAM males acquired at this dose. A Pearson $\chi^{2}$ test indicated that the percentage of animals that reached the acquisition criteria differed by group, $\chi^{2}(4, n=92)=23.5$, $p<0.0001$. By the end of Week 2, $100 \%$ of OVX $+\mathrm{E}$ had acquired self-administration behavior, and $47 \%$ of OVX $+\mathrm{E}$ $+\mathrm{P}, 55.6 \%$ of OVX females, $53.8 \%$ of CAST, and $28.6 \%$ of SHAM males reached criterion. The number of animals that reached the acquisition criteria differed by group in Week 2 , $\chi^{2}(4, n=68)=16.7, p<0.002$. By the end of Week 3 , almost all rats in all groups had acquired self-administration behavior $(100 \%$ of OVX $+\mathrm{E}, 77.8 \%$ of OVX $+\mathrm{E}+\mathrm{P}, 85.7 \%$ of OVX, $81.8 \%$ of CAST, and $87.5 \%$ of SHAM males). There were no significant differences in the percentage of rats that acquired cocaine by this point, $\chi^{2}(4, n=47)=2.78$, $p<0.595$.

\section{Experiment 2: Effect of Estradiol Administration in CAST Male Rats on Acquisition of Cocaine Self-Administration}

Estradiol did not enhance cocaine self-administration in CAST male rats. Figure 4 shows the average number of cocaine infusions taken by each group during the 3 weeks of testing. During Week 1 ( $0.3 \mathrm{mg} / \mathrm{kg} /$ infusion; Figure $4 \mathrm{a})$, there was a main effect of hormone treatment $\left(\mathrm{F}_{(5,20)}=10.98, \quad p<0.0001\right)$, an effect of test session $\left.\mathrm{F}_{(4,5)}=8.4, p<0.0001\right)$, and an interaction of hormone group and test session $\left.\mathrm{F}_{(20,501)}=1.6, p<0.046\right)$. Post hoc comparisons indicated that on the first 3 days of testing, there were no differences among groups. On day 4, the OVX
$+\mathrm{E}$ group took more infusions than all of the male groups $(p<0.003)$, and on day 5 , the OVX $+\mathrm{E}$ group took more infusions than all other groups $(p<0.0029)$. None of the other groups differed from one another. There were no significant differences among groups in nose pokes at the inactive hole. During Week 2 ( $0.4 \mathrm{mg} / \mathrm{kg} /$ infusion; Figure $4 \mathrm{~b}$ ), there was a main effect of hormone treatment $\left(F_{(5,20)}=18.99, \quad p<0.0001\right)$, no effect of test session $\left(\mathrm{F}_{(4,5)}=1.23, p<0.299\right)$, and no group by test session interaction $\left(\mathrm{F}_{(20,461)}=0.21, p<0.99\right)$. Again, OVX $+\mathrm{E}$ females took more infusions than all other groups $(p<0.0016)$, which did not differ from one another, and there were no group difference in nose pokes at the inactive hole. Since we had previously seen a difference between OVX and CAST groups in acquisition at $0.4 \mathrm{mg} / \mathrm{kg} /$ infusion ( $\mathrm{Hu}$ et al, 2004), we did planned comparisons and found that only on day 9 did OVX animals receive more infusions than CAST $\left.\left(\mathrm{F}_{(1,41)}\right)=3.94, p=0.05\right)$. During Week $3(0.5 \mathrm{mg} / \mathrm{kg} /$ infusion; Figure $4 \mathrm{c})$, there was a main effect of hormone treatment $\left(\mathrm{F}_{(5,20)}=4.35\right.$, $p<0.0007)$, no effect of test session $\left(\mathrm{F}_{(4,5)}=1.997\right.$, $p<0.095)$, and no group by test session interaction $\left(\mathrm{F}_{(20,358)}=0.11, p<0.99\right)$. Once again, the OVX $+\mathrm{E}$ females took more infusions than all other groups, which did not differ from one another.

Table 1 shows the percentage of rats that acquired selfadministration as a function of group and week of testing (dose). During Week 1, 41\% of the OVX $+\mathrm{E}$ females acquired self-administration behavior, whereas only nine of OVX females, $5 \%$ of CAST, $6 \%$ of CAST + E, and $5 \%$ of SHAM males acquired at this dose. A Pearson $\chi^{2}$ test indicated that the percentage of animals that reached the acquisition criteria differed by group, $\chi^{2}(4$, $n=113)=18.36, p<0.001$. By the end of Week $2,74 \%$ of $\mathrm{OVX}+\mathrm{E}$ had acquired self-administration behavior, and $33 \%$ of OVX females, $44 \%$ of CAST, $31 \%$ of CAST $+\mathrm{E}$, and $28 \%$ of SHAM males reached criterion. The number of animals that reached the acquisition criteria differed by group in Week $2, \chi^{2}(4, n=96)=10.96, p<0.027$. By the end of Week 3, most rats had acquired self-administration behavior $(79 \%$ of OVX $+\mathrm{E}, 68 \%$ of OVX females, $60 \%$ of CAST, $50 \%$ of CAST $+\mathrm{E}$, and $50 \%$ of SHAM males). There were no significant differences in the percentage of rats that acquired cocaine by this point, $\chi^{2}(4, n=80)=3.78$, $p<0.437$.

\section{DISCUSSION}

In the present study, we replicated our earlier observation that in OVX rats, treatment with estradiol facilitates the acquisition of cocaine self-administration behavior ( $\mathrm{Hu}$ et al, 2004). More importantly, we now report for the first time that (1) concurrent administration of progesterone with estradiol counteracts this effect of estradiol, and (2) a dose of estradiol that enhances self-administration in female rats has no effect on cocaine self-administration behavior in male rats. Thus, the effects of estradiol on the acquisition of cocaine self-administration are sexually dimorphic, and progesterone antagonizes the effects of estradiol in female rats. 
Table I Percentage of Rats that Acquired Cocaine Self-Administration in Experiment 2

\begin{tabular}{lccccrr}
\hline Week & Dose cocaine & OVX+E (\%) & OVX (\%) & CAST (\%) & CAST+E (\%) & SHAM males (\%) \\
\hline 1 & $0.3 \mathrm{mg} / \mathrm{kg} / \mathrm{inf}$ & 41 & 9 & 5 & 6 & 5 \\
2 & $0.4 \mathrm{mg} / \mathrm{kg} / \mathrm{inf}$ & 74 & 33 & 44 & 51 & 28 \\
3 & $0.5 \mathrm{mg} / \mathrm{kg} / \mathrm{inf}$ & 79 & 68 & 60 & 50 & 50 \\
\hline
\end{tabular}
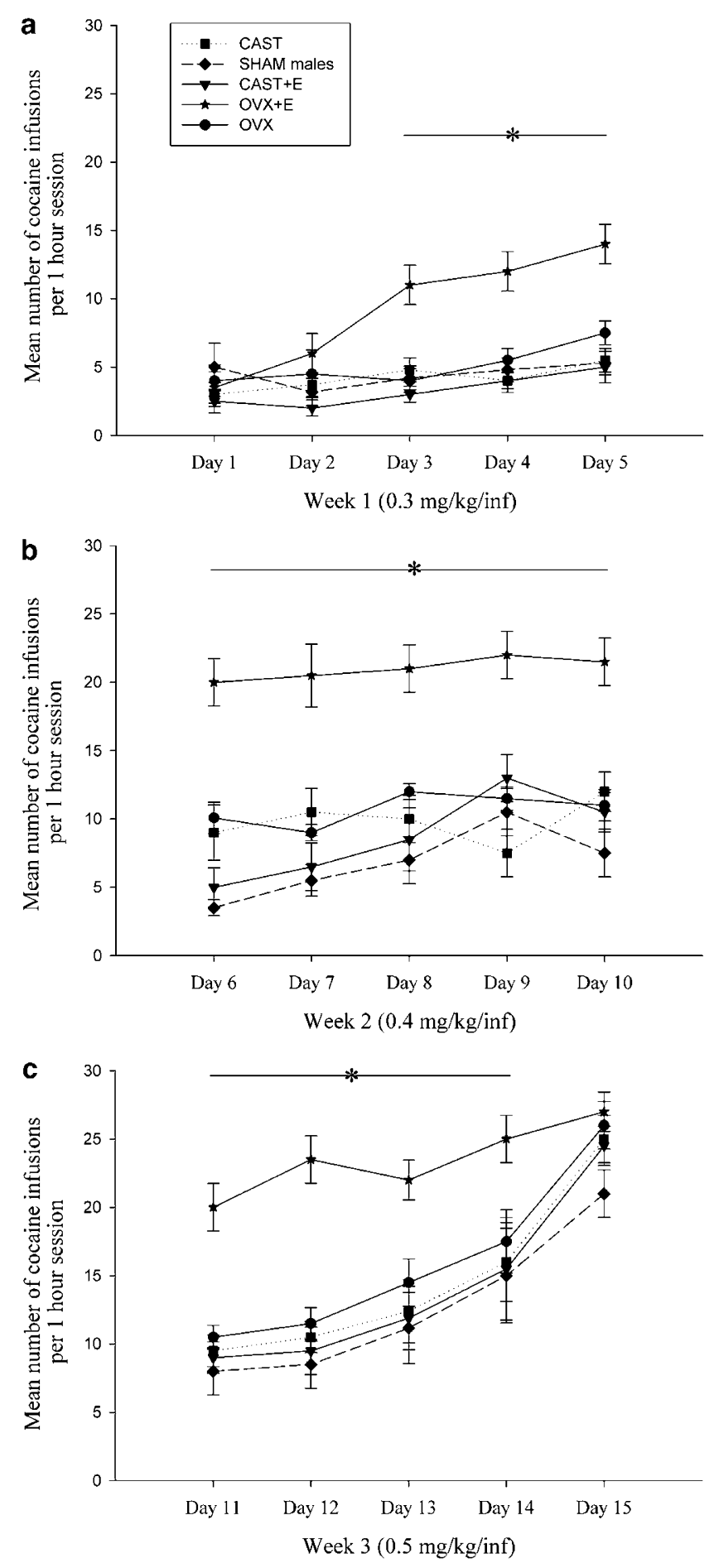

\section{Relevance to Existing Literature}

The facilitating effect of estradiol on cocaine self-administration behavior is consistent with the results from a number of previous studies reporting that estradiol facilitates the psychomotor activating and rewarding effects of psychomotor stimulant drugs (Becker et al, 1982; Becker and Cha, 1989; Roberts et al, 1989; Lynch et al, 2000, 2001; Sell et al, 2002; Hu and Becker, 2003). This effect of estradiol may be mediated by its well-characterized actions on dopamine (DA) neurotransmission (Robinson et al, 1982; Di Paolo et al, 1985, 1988; Levesque and Di Paolo, 1988; Levesque et al, 1989; Morissette and Di Paolo, 1993a, b; Xiao and Becker, 1994; Thompson and Moss, 1994; Xiao et al, 2003; see $\mathrm{Hu}$ et al, 2004 for further discussion).

Methodological variations in self-administration studies can, however, affect the results. For example, the pattern of responding in this study is similar to the $\mathrm{Hu}$ et al (2004) study, but in the morning test sessions used in this study, animals responded less overall than those in the $\mathrm{Hu}$ et al (2004) study, where animals were tested in the afternoon. We also did not find a significant difference between OVX and CAST in responding for $0.4 \mathrm{mg} / \mathrm{kg}$ cocaine during Week 2 , in both experiments. This may be because animals were responding less overall. It should be noted that time of day

Figure 4 (a) Cocaine self-administration over the first five test sessions-Experiment 2. This figure shows the mean number of cocaine infusions ( \pm SEM) taken by rats in the male: CAST, CAST + E, SHAM; and female: $O V X+E$ and $O V X$ groups during the first week of testing at $0.3 \mathrm{mg} / \mathrm{kg} /$ infusion. On the first 3 days of testing, there were no differences among the groups. On day 4, the OVX $+E$ group attained more cocaine infusions than all of the male groups $(p<0.003)$, and on day 5 , the OVX + E group attained more infusions than all other groups $(p<0.0029)$. The other groups did not differ from one another. There were no group differences in activity at the inactive hole. (b) Cocaine self-administration during Week 2 at $0.4 \mathrm{mg} / \mathrm{kg} /$ infusion-Experiment 2. This figure shows the mean number of cocaine infusions $( \pm$ SEM) taken by rats in the male: CAST, CAST + E, SHAM; and female: OVX $+E$ and OVX groups during the second week of testing at $0.4 \mathrm{mg} / \mathrm{kg} /$ infusion. The $\mathrm{OVX}+\mathrm{E}$ group attained more cocaine infusions than all other groups $(p<0.0016)$, which did not differ from one another. There were no group differences in activity at the inactive hole. The $\mathrm{OVX}+\mathrm{E}$ and $\mathrm{OVX}$ groups met the criterion for acquisition at this dose. (c) Cocaine self-administration during Week 3 at $0.5 \mathrm{mg} / \mathrm{kg} /$ infusion - Experiment 2. This figure shows the number of cocaine infusions $( \pm$ SEM) taken by rats in the male: CAST, CAST $+E$, SHAM; and female: OVX $+E$ and OVX groups during the third week of testing at $0.5 \mathrm{mg} / \mathrm{kg} /$ infusion. On days $1 \mathrm{I}-13$, the $\mathrm{OVX}+\mathrm{E}$ group attained more cocaine infusions than all other groups, which did not differ from one another. There were no group differences in activity at the inactive hole. All groups met the criterion for acquisition at this dose. 
has previously been reported to affect cocaine self-administration (Baird, 1999; Baird and Gauvin, 2000). In addition, whereas many studies have found that females exhibit greater cocaine self-administration than male rats (Roberts et al, 1989; Hu et al, 2004; Lynch et al, 2001), Caine et al reported that male rats acquired self-administration of $1 \mathrm{mg} / \mathrm{kg} /$ infusion cocaine faster than did females, and that estrogen did not influence cocaine self-administration behavior (Caine et al, 2004). As Caine et al (2004) mention, varying results are attained with different doses of cocaine. One advantage to using lower doses is being able to parse out effects of sex differences and gonadal hormones that are obscured at higher cocaine doses.

Of particular interest here is the finding that progesterone counteracted the effect of estradiol. The general idea that progesterone can inhibit behaviors previously activated by estradiol is not new. For example, the activation of progesterone receptors in sexually receptive females is known to inhibit sexual receptivity (Reading and Blaustein, 1984). Given that motivated behaviors, such as sexual behavior and drug-taking behavior, are mediated by overlapping neural systems (Everitt et al, 1974, 1975; Kelley and Berridge, 2002), including DA systems (Mermelstein and Becker, 1995; Pfaus et al, 1990; Phillips et al, 1991; Vezina, 1993), perhaps it is not surprising that progesterone has inhibitory effects on cocaine self-administration behavior. Furthermore, several recent publications have postulated that progesterone attenuates cocaine-induced behavioral activation (Sell et al, 2000; Russo et al, 2003; Festa and Quinones-Jenab, 2004); however, this is the first study to demonstrate that progesterone inhibits cocaine-taking behavior in rats.

Estradiol and progesterone are normally secreted together during the luteal phase of the menstrual cycle in women and during pregnancy in most mammals, times that are not generally thought of as aversive. Thus, inhibited cocaine self-administration is not likely due to an aversive subjective state. In female rats, chronic estradiol and progesterone treatment was found to enhance conditioned place preference for cocaine in female rats, relative to controls (Russo et al, 2003), this suggests that estradiol and progesterone do not create an aversive subjective effect in rats. The hormone treatment paradigm used in the study reported here is quite different from that used by Russo et al (2003), so future studies will need to investigate whether acute treatment with estradiol and progesterone affects conditioned place preference for cocaine.

\section{Possible Mechanisms of Progesterone Action}

How might progesterone exert its inhibitory effects at a psychological level? One interesting hypothesis comes from considering the effects of progesterone on the subjective effects of cocaine in humans. In normally cycling women, progesterone secretion occurs concurrently with estradiol secretion during the luteal phase of the cycle (McCarthy and Becker, 2002), and the subjective effects of cocaine are attenuated during the luteal phase, as compared to the follicular phase, of the menstrual cycle (Sofuoglu et al, 1999; Evans et al, 2002). Furthermore, exogenous progesterone administration is reported to attenuate some of the subjective responses to cocaine in cocaine users (Sofuoglu et al, 2002, 2004). Progesterone alone may be effective in these situations because of circulating endogenous estradiol in both men and women. Thus, the combination of estradiol and progesterone may diminish some subjective effects of cocaine, relative to those seen when estradiol alone is elevated. Presumably, positive reinforcing effects contribute to the acquisition of cocaine self-administration behavior in both humans and rats. If acute estradiol plus progesterone treatment, as used in the study reported here, diminishes the reinforcing effects of cocaine in rats, then this could contribute to the findings reported. On the other hand, given the findings of Russo et al (2003), effects of hormone treatment on the subjective hedonic value of cocaine do not necessarily underlie the influence of hormones on acquisition of self-administration of cocaine.

Cocaine self-administration is thought to be mediated, at least in part, by increased DA neurotransmission. So, another hypothesis comes from considering the actions of progesterone on DA neurotransmission. Although DA systems are hypothesized to be uninvolved in mediating the positive subjective effects (euphoria) of cocaine (Gawin and Kleber, 1986; Brauer and De Wit, 1997; Berridge and Robinson, 1998), they are thought to be important in mediating the reinforcing and incentive motivational effects of cocaine (Yokel and Wise, 1975; Wise and Rompre, 1989; Robinson and Berridge, 1993, 2000; White and Kalivas, 1998; Berridge and Robinson, 1998; Wise and Bozarth, 1987). Importantly, progesterone antagonizes estradiol's enhancement of DA. For example, 30 min after progesterone was administered to estradiol-primed rats, AMPH-stimulated DA release from striatal tissue in vitro was enhanced. However, $24 \mathrm{~h}$ after progesterone administration, AMPHstimulated DA release from striatal tissue in vitro was inhibited (Dluzen and Ramirez, 1984). This is consistent with the inhibition shown in the present study, given that inhibitory effects of progesterone on acquisition of cocaine self-administration were not apparent until after day 2 (Figure 1). That progesterone can both enhance and inhibit stimulated release of DA from the striatum has been demonstrated in a series of studies by Dluzen and Ramirez (1984, 1987, 1989, 1990a, b, 1991). While the mechanism(s) mediating these effects have not yet been elucidated, our results suggest that one possible consequence of these effects is a reduction in DA neurotransmission, and consequently, a reduction in the reinforcing or incentive motivational effects of drugs of abuse such as cocaine. This could then inhibit the acquisition of cocaine self-administration behavior in female rats.

A third (and not mutually exclusive) hypothesis comes from considering the effect of progesterone on changes in DA neurotransmission associated with the development of behavioral sensitization, which is an animal model of craving for addictive substances. Repeated exposure to cocaine results in sensitization of psychomotor and incentive motivational effects, which are attributed in part to changes in DA neurotransmission (Robinson and Berridge, 1993; White and Kalivas, 1998; Wise and Bozarth, 1987). Indeed, a progressive sensitization of neural systems that mediate incentive motivational effects of cocaine, produced by daily drug exposure, may contribute to the acquisition of self-administration behavior. Estradiol has been shown to facilitate the development of behavioral 
sensitization and associated changes in DA (Peris et al, 1991; $\mathrm{Hu}$ and Becker, 2003). The effect of estradiol on sensitization is antagonized by progesterone. For example, OVX rats that received chronic estradiol and progesterone administration had both a lower frequency of cocaineinduced stereotyped and locomotor behaviors and lower AMPH-stimulated DA release from striatal slices in vitro than OVX rats that received estradiol alone (Peris et al, 1991). Thus, progesterone may antagonize the facilitory effect of estradiol on self-administration by antagonizing incentive sensitization. Of course, the ideas that progesterone may act by altering the subjective effects of cocaine, by directly affecting neural systems that mediate core incentive motivational processes, or by influencing drug-induced plasticity (sensitization) in these systems, are not mutually exclusive-progesterone could simultaneously affect any and all of these processes.

Finally, the effects of estradiol and progesterone on the DA system could be mediated indirectly through their effects on other neurons. For example, we have shown that estradiol inhibits L-type calcium current on medium spiny GABAergic neurons in the striatum (Mermelstein et al, 1996), and we have recently shown that estradiol rapidly inhibits KCl-stimulated GABA overflow in dialysate from the striatum (Watson et al, 2004). Thus, estradiol and progesterone may act by modulating GABAergic release, thereby modulating dopaminergic function indirectly.

\section{Effects of Gonadal Hormones on Male Cocaine Self-Administration}

Estradiol treatment 30 min prior to the self-administration session enhanced acquisition of cocaine self-administration in OVX females, but not CAST males (Figures 1 and 4). Thus, the brains of males and females differ in their response to estradiol. This suggests that there are organizational effects of early hormone exposure on the neural system through which estradiol influences cocaine selfadministration.

Results of studies investigating the effects of castration and testosterone on the behavioral response to cocaine have been inconsistent. For example, several studies have shown no effect of castration on cocaine self-administration (this study and $\mathrm{Hu}$ et al, 2004), behavioral sensitization to cocaine (Hu and Becker, 2003), or acute or chronic cocaine administration (van Haaren and Meyer, 1991). However, others have seen differences between intact and castrated males in the behavioral response to cocaine (Chin et al, 2002) and AMPH (Robinson, 1984). Exogenous testosterone administration to CAST males did not affect behavioral sensitization to AMPH (Forgie and Stewart, 1994), but Chen et al (2003) indicated that chronic testosterone administration to CAST males reduced sensitization (Chen et al, 2003). Therefore, it is not clear where or how androgens are acting to influence the acquisition of cocaine self-administration or other cocaine-mediated behaviors.

Sex differences in response to exogenous estradiol administration are likely due to sex differences in the influence of circulating gonadal hormones on the brain. In females, but not males, circulating estradiol may act on brain systems that mediate drug reward and modulate drugtaking behavior. Estradiol has been shown to influence DA activity in brain regions that are important in mediating drug reward. Estradiol increases AMPH-stimulated DA release from the striatum (Castner et al, 1993; Becker and Rudick, 1999) and attenuates DA reuptake in the nucleus accumbens (Thompson, 1999). Although estradiol affects DA-mediated behaviors and DA neurotransmission in females, it does not appear to do so in males. For example, exogenous estradiol administration to castrated males did not enhance AMPH-stimulated stereotyped head or forelimb movements, or AMPH-stimulated DA in dialysate from the striatum, although it enhanced both measures in OVX females (Castner et al, 1993). Since mesotelencephalic DA systems are thought to mediate reward (Wise and Bozarth, 1987), it is likely that the ability of estradiol to facilitate DA activity is related to estradiol's facilitation of cocaine selfadministration behavior in females.

Given the influence of ovarian hormones on responses to cocaine and other drugs of abuse (Carroll et al, 2004), it is important to understand the mechanisms by which these hormones exert their influence. Although the effects of estradiol administration on transcription factors, DA neurotransmission, and cocaine-mediated behaviors have been investigated in some depth, the effect of progesterone administration on these processes has not been well explored. Appreciating the influence of progesterone will contribute to our ability to characterize accurately neuroendocrine influences that predict vulnerability to cocaine abuse.

\section{Conclusions}

Inherent sex differences in brain organization and sex differences in the effects of circulating ovarian hormones are likely to be important contributing factors to women's more deleterious patterns of cocaine abuse. Effects of circulating ovarian hormones may facilitate the acquisition of a cocaine habit for women, while organizational brain differences may keep women vulnerable. As the likelihood of developing lifetime dependence upon cocaine is greater for women than men (Kandel et al, 1995), incorporating considerations of gender and hormonal status is critical to designing appropriate prevention, intervention, and treatment strategies for women.

\section{ACKNOWLEDGEMENTS}

This research was supported by a grant from the NIH to JBB R01 DA012677.

\section{REFERENCES}

Baird TJ (1999). Time-of-day influences on rates and patterns of cocaine self-administration and pharmacokinetics in the rat. FASEB J 13: A1108.

Baird TJ, Gauvin D (2000). Characterization of cocaine selfadministration and pharmacokinetics as a function of time of day in the rat. Pharmacol Biochem Behav 65: 289-299.

Becker JB (1999). Gender differences in dopaminergic function in striatum and nucleus accumbens. Pharmacol Biochem Behav 64: 803-812. 
Becker JB, Cha JH (1989). Estrous cycle-dependent variation in amphetamine-induced behaviors and striatal dopamine release assessed with microdialysis. Behav Brain Res 35: 117-125.

Becker JB, Robinson TE, Lorenz KA (1982). Sex differences and estrous cycle variations in amphetamine-elicited rotational behavior. Eur J Pharmacol 80: 65-72.

Becker JB, Rudick CN (1999). Rapid effects of estrogen or progesterone on the amphetamine-induced increase in striatal dopamine are enhanced by estrogen priming: a microdialysis study. Pharmacol Biochem Behav 64: 53-57.

Berridge KC, Robinson TE (1998). What is the role of dopamine in reward: hedonic impact, reward learning, or incentive salience? Brain Res Brain Res Rev 28: 309-369.

Brauer LH, De Wit H (1997). High dose pimozide does not block amphetamine-induced euphoria in normal volunteers. Pharmacol Biochem Behav 56: 265-272.

Caine SB, Bowen CA, Yu G, Zuzga D, Negus SS, Mello NK (2004). Effect of gonadectomy and gonadal hormone replacement on cocaine self-administration in female and male rats. Neuropsychopharmacology 29: 929-942.

Carroll ME, Lynch WJ, Roth ME, Morgan AD, Cosgrove KP (2004). Sex and estrogen influence drug abuse. Trends Pharmacol Sci 25: 273-279.

Carroll ME, Morgan AD, Lynch WJ, Campbell UC, Dess NK (2002). Intravenous cocaine and heroin self-administration in rats selectively bred for differential saccharin intake: phenotype and sex differences. Psychopharmacology 161: 304-313.

Castner SA, Xiao L, Becker JB (1993). Sex differences in striatal dopamine: in vivo microdialysis and behavioral studies. Brain Res 610: 127-134.

Chen R, Osterhaus G, McKerchar T, Fowler SC (2003). The role of exogenous testosterone in cocaine-induced behavioral sensitization and plasmalemmal or vesicular dopamine uptake in castrated rats. Neurosci Lett 351: 161-164.

Chin J, Sternin O, Wu HB, Burrell S, Lu D, Jenab S et al (2002). Endogenous gonadal hormones modulate behavioral and neurochemical responses to acute and chronic cocaine administration. Brain Res 945: 123-130.

Di Paolo T, Falardeau P, Morissette M (1988). Striatal D-2 dopamine agonist binding-sites fluctuate during the rat estrous-cycle. Life Sci 43: 665-672.

Di Paolo T, Rouillard C, Bedard P (1985). 17 Beta-estradiol at a physiological dose acutely increases dopamine turnover in rat brain. Eur J Pharmacol 117: 197-203.

Disshon KA, Boja JW, Dluzen DE (1998). Inhibition of striatal dopamine transporter activity by 17 beta-estradiol. Eur J Pharmacol 345: 207-211.

Dluzen DE, Ramirez VD (1984). Bimodal effect of progesterone on in vitro dopamine function of the rat corpus striatum. Neuroendocrinology 39: 149-155.

Dluzen DE, Ramirez VD (1987). Intermittent infusion of progesterone potentiates whereas continuous infusion reduces amphetamine-stimulated dopamine release from ovariectomized estrogen-primed rat striatal fragments superfused in vitro. Brain Res 406: 1-9.

Dluzen DE, Ramirez VD (1989). Progesterone effects upon dopamine release from the corpus striatum of female rats. I. Evidence for interneuronal control. Brain Res 476: 332-337.

Dluzen DE, Ramirez VD (1990a). In vitro progesterone modulates amphetamine-stimulated dopamine release from the corpus striatum of castrated male rats treated with estrogen. Neuroendocrinology 52: 517-520.

Dluzen DE, Ramirez VD (1990b). In vitro progesterone modulation of amphetamine-stimulated dopamine release from the corpus striatum of ovariectomized estrogen-treated female rats: response characteristics. Brain Res 517: 117-122.

Dluzen DE, Ramirez VD (1991). Modulatory effects of progesterone upon dopamine release from the corpus striatum of ovariectomized estrogen-treated rats are stereo-specific. Brain Res 538: 176-179.

Evans SM, Haney M, Foltin RW (2002). The effects of smoked cocaine during the follicular and luteal phases of the menstrual cycle in women. Psychopharmacology 159: 397-406.

Everitt BJ, Fuxe K, Hokfelt FT, Jonsson G (1975). Role of monoamines in the control by hormones of sexual receptivity in the female rat. J Comp Physiol Psychol 89: 556-572.

Everitt BJ, Fuxe K, Hokfelt T (1974). Inhibitory role of dopamine and 5-hydroxytryptamine in the sexual behaviour of female rats. Eur J Pharmacol 29: 187-191.

Festa ED, Quinones-Jenab V (2004). Gonadal hormones provide the biological basis for sex differences in behavioral responses to cocaine. Horm Behav 46: 509-519.

Forgie ML, Stewart J (1994). Sex-differences in the locomotoractivating effects of amphetamine - role of circulating testosterone in adulthood. Physiol Behav 55: 639-644.

Gawin F, Kleber H (1986). Pharmacological treatments of cocaine abuse. Psychiatric Clin N Am 9: 573-583.

Greenblatt J, Gfroerer J (1998). Self-reported problems associated with drug use. In: SAMHSA (ed). Analysis of Substance Abuse and Treatment Need Issues. US Department of Health and Human Services: Rockville, MD. pp 71-88.

Griffin ML, Weiss RD, Mirin SM, Lange U (1989). A comparison of male and female cocaine abusers. Arch Gen Psychiatry 46: $122-126$

Grimm JW, See RE (1997). Cocaine self-administration in ovariectomized rats is predicted by response to novelty, attenuated by 17-beta estradiol, and associated with abnormal vaginal cytology. Physiol Behav 61: 755-761.

Hecht GS, Spear NE, Spear LP (1999). Changes in progressive ratio responding for intravenous cocaine throughout the reproductive process in female rats. Dev Psychobiol 35: 136-145.

$\mathrm{Hu}$ M, Becker JB (2003). Effects of sex and estrogen on behavioral sensitization to cocaine in rats. J Neurosci 23: 693-699.

$\mathrm{Hu}$ M, Crombag HS, Robinson TE, Becker JB (2004). Biological basis of sex differences in the propensity to self-administer cocaine. Neuropsychopharmacology 29: 81-85.

Justice AJ, de Wit H (1999). Acute effects of $d$-amphetamine during the follicular and luteal phases of the menstrual cycle in women. Psychopharmacology (Berl) 145: 67-75.

Kandel D, Warner L, Kessler R (1995). The epidemiology of substance abuse and dependence among women. In: Wetherington $\mathrm{CL}$, Roman $\mathrm{AB}$ (eds). Drug Addiction Research and the Health of Women. US Department of Health and Human Services: Bethesda, MD. pp 105-130.

Kelley AE, Berridge KC (2002). The neuroscience of natural rewards: relevance to addictive drugs. J Neurosci 22: 33063311.

Kosten TA, Gawin FH, Kosten TR, Rounsaville BJ (1993). Gender differences in cocaine use and treatment response. J Subst Abuse Treat 10: 63-66.

Levesque D, Di Paolo T (1988). Rapid conversion of high into low striatal D2-dopamine receptor agonist binding states after an acute physiological dose of 17-beta-estradiol. Neurosci Lett 88: 113-118.

Levesque D, Gagnon S, Di Paolo T (1989). Striatal D1 dopamine receptor density fluctuates during the rat estrous-cycle. Neurosci Lett 98: 345-350.

Lex BW (1991). Some gender differences in alcohol and polysubstance users. Health Psychol 10: 121-132.

Lynch WJ, Arizzi MN, Carroll ME (2000). Effects of sex and the estrous cycle on regulation of intravenously self-administered cocaine in rats. Psychopharmacology (Berl) 152: 132-139.

Lynch WJ, Carroll ME (1999). Sex differences in the acquisition of intravenously self-administered cocaine and heroin in rats. Psychopharmacology 144: 77-82. 
Lynch WJ, Roth ME, Carroll ME (2002). Biological basis of sex differences in drug abuse: preclinical and clinical studies. Psychopharmacology 164: 121-137.

Lynch WJ, Roth ME, Mickelberg JL, Carroll ME (2001). Role of estrogen in the acquisition of intravenously self- administered cocaine in female rats. Pharmacol Biochem Behav 68: 641-646.

McCarthy MM, Becker JB (2002). Neuroendocrinology of sexual behavior in the female. In: Becker JB, Breedlove SM, Crews D, McCarthy MM (eds). Behavioral Endocrinology. The MIT Press: Cambridge, MA. pp 117-152.

Mermelstein PG, Becker JB (1995). Increased extracellular dopamine in the nucleus accumbens and striatum of the female rat during paced copulatory behavior. Behav Neurosci 109: 354-365.

Mermelstein PG, Becker JB, Surmeier DJ (1996). Estrogen reduces calcium currents in rat neostriatal neurons via a membrane receptor. J Neurosci 16: 595-604.

Morissette M, Di Paolo T (1993a). Effect of chronic estradiol and progesterone treatments of ovariectomized rats on brain dopamine uptake sites. J Neurochem 60: 1876-1883.

Morissette M, Di Paolo T (1993b). Sex and estrous-cycle variations of rat striatal dopamine uptake sites. Neuroendocrinology 58: 16-22.

Peris J, Decambre N, Coleman-Hardee ML, Simpkins JW (1991). Estradiol enhances behavioral sensitization to cocaine and amphetamine-stimulated striatal $\left[{ }^{3} \mathrm{H}\right]$ dopamine release. Brain Res 566: 255-264.

Perrotti LI, Russo SJ, Fletcher H, Chin J, Webb T, Jenab S et al (2001). Ovarian hormones modulate cocaine-induced locomotor and stereotypic activity. Ann NY Acad Sci 937: 202-216.

Pfaus JG, Damsma G, Nomikos GG, Wenkstern DG, Blaha CD, Phillips AG et al (1990). Sexual behavior enhances central dopamine transmission in the male rat. Brain Res 530: 345-348.

Phillips AG, Pfaus JG, Blaha CD (1991). Dopamine and motivated behavior: insights provided by in vivo analyses. In: Willner P, Scheel-Kruger J (eds). The Mesolimbic Dopamine System: From Motivation to Action. John Wiley and Sons Ltd: Chichester, UK. pp 199-224.

Quinones-Jenab V, Perrotti LI, McMonagle J, Ho A, Kreek MJ (2000). Ovarian hormone replacement affects cocaine-induced behaviors in ovariectomized female rats. Pharmacol Biochem Behav 67: 417-422.

Reading DS, Blaustein JD (1984). The relationship between heat abbreviation and neural progestin receptors in female rats. Physiol Behav 32: 973-981.

Roberts DC, Bennett SA, Vickers GJ (1989). The estrous cycle affects cocaine self-administration on a progressive ratio schedule in rats. Psychopharmacology 98: 408-411.

Robinson T (1984). Behavioral sensitization: characterization of enduring changes in rotational behavior produced by intermittent injections of amphetamine in male and female rats. Psychopharmacology 84: 466-475.

Robinson TE, Berridge KC (1993). The neural basis of drug craving: an incentive-sensitization theory of addiction. Brain Res Rev 18: 247-291.

Robinson TE, Berridge KC (2000). The psychology and neurobiology of addiction: an incentive-sensitization view. Addiction 95: S91-S117.

Robinson TE, Camp DM, Jacknow DS, Becker JB (1982). Sex differences and estrous cycle dependent variation in rotational behavior elicited by electrical stimulation of the mesostriatal dopamine system. Behav Brain Res 6: 273-287.

Russo SJ, Festa ED, Fabian SJ, Gazi FM, Kraish M, Jenab S et al (2003). Gonadal hormones differentially modulate cocaineinduced conditioned place preference in male and female rats. Neuroscience 120: 523-533.
Sell S, Thomas M, Cunningham K (2002). Influence of estrous cycle and estradiol on behavioral sensitization to cocaine in female rats. Drug Alcohol Depend 67: 281-290.

Sell SL, Scalzitti JM, Thomas ML, Cunningham KA (2000). Influence of ovarian hormones and estrous cycle on the behavioral response to cocaine in female rats. J Pharmacol Exp Therap 293: 879-886.

Sircar R, Kim D (1999). Female gonadal hormones differentially modulate cocaine-induced behavioral sensitization in Fischer, Lewis, and Sprague-Dawley rats. J Pharmacol Exp Therap 289: $54-65$.

Sofuoglu M, Babb DA, Hatsukami DK (2002). Effects of progesterone treatment on smoked cocaine response in women. Pharmacol Biochem Behav 72: 431-435.

Sofuoglu M, Dudish-Poulsen S, Nelson D, Pentel PR, Hatsukami DK (1999). Sex and menstrual cycle differences in the subjective effects from smoked cocaine in humans. Exp Clin Psychopharmacol 7: 274-283.

Sofuoglu M, Mitchell E, Kosten TR (2004). Effects of progesterone treatment on cocaine responses in male and female cocaine users. Pharmacol Biochem Behav 78: 699-705.

Thompson TL (1999). Attenuation of dopamine uptake in vivo following priming with estradiol benzoate. Brain Res 834: 164-167.

Thompson TL, Moss RL (1994). Estrogen regulation of dopamine release in the nucleus accumbens: genomic- and nongenomicmediated effects. J Neurochem 62: 1750-1756.

van Haaren F, Meyer ME (1991). Sex differences in locomotor activity after acute and chronic cocaine administration. Pharmacol Biochem Behav 39: 923-927.

Verimer T, Arneric SP, Long JP, Walsh BJ, Abou Zeit-Har MS (1981). Effects of ovariectomy, castration, and chronic lithium chloride treatment on stereotyped behavior in rats. Psychopharmacology 75: 273-276.

Vezina P (1993). Amphetamine injected into the ventral tegmental area sensitizes the nucleus accumbens dopaminergic response to systemic amphetamine: an in vivo microdialysis study in the rat. Brain Res 605: 332-337.

Watson C, Hu M, Kennedy R, Becker J (2004). Estradiol Attenuates the GABA Increase by High $\mathrm{KCl}$ in Dialysate from Striatum. Society for Neuroscience: Washington, DC.

White FJ, Kalivas PW (1998). Neuroadaptations involved in amphetamine and cocaine addiction. Drug Alcohol Depend 51: 141-153.

White S, Uphouse L (2004). Estrogen and progesterone dosedependently reduce disruptive effects of restraint on lordosis behavior. Horm Behav 45: 201-208.

White TL, Justice AJH, de Wit H (2002). Differential subjective effects of D-amphetamine by gender, hormone levels and menstrual cycle phase. Pharmacol Biochem Behav 73: 729-741.

Wise RA, Bozarth MA (1987). A psychomotor stimulant theory of addiction. Psychol Rev 94: 469-492.

Wise RA, Rompre PP (1989). Brain dopamine and reward. Annu Rev Psychol 40: 191-225.

Xiao L, Becker JB (1994). Quantitative microdialysis determination of extracellular striatal dopamine concentration in male and female rats: effects of estrous cycle and gonadectomy. Neurosci Lett 180: 155-158.

Xiao L, Jackson LR, Becker JB (2003). The effect of estradiol in the striatum is blocked by ICI 182780 but not tamoxifen: pharmacological and behavioral evidence. Neuroendocrinology 77: 239-245.

Yokel RA, Wise RA (1975). Increased lever pressing for amphetamine after pimozide in rats: implications for a dopamine theory of reward. Science 187: 547-549. 